\title{
Trends in the atmospheric water vapor content from ground-based GPS: the impact of the elevation cutoff angle
}

\author{
Tong Ning and Gunnar Elgered
}

\begin{abstract}
We used 14 years of data from 12 GPS sites in Sweden and Finland to estimate trends in the atmospheric integrated water vapor (IWV) for 8 different elevation cutoff angles, from $5^{\circ}$ to $40^{\circ}$, for the observations used in the analyses. These trends were compared to the corresponding trends obtained from radiosonde data at 7 nearby $(<120 \mathrm{~km})$ sites. The results show a variation in the correlation of the trends between the two techniques for different elevation cutoff angles. The highest correlation coefficient of 0.88 is obtained for the $25^{\circ}$ solution, whereas the smallest root-mean-square (RMS) differences between the IWV estimates themselves are obtained mainly for elevation cutoff angles of $10^{\circ}$ and $15^{\circ}$. The results show that due to elevation-angle-dependent systematic errors that vary with time the elevation cutoff angle giving the best agreement between radiosonde and GPS for individual IWV estimates is not necessarily the optimum when estimating linear trends. The correlation between the trends from the two completely independent techniques is strong evidence that the two techniques provide information on the IWV trends although the true individual values are too small to be uniquely detected.
\end{abstract}

Index Terms

GPS, atmospheric integrated water vapor, elevation cutoff angles, radiosondes.

\section{INTRODUCTION}

Water vapor is an important greenhouse gas. An increase of $20 \%$ of the water vapor content in the tropics would result in approximately the same impact as a doubling of the carbon dioxide concentration [1]. Therefore, accurate measurements of the atmospheric water vapor content are important. They are however in general difficult and/or costly to carry out over long time periods using traditional techniques.

Based on the propagation time of Global Positioning System (GPS) signals the atmospheric integrated water vapor (IWV) can be estimated above receivers on the ground. With a relatively high temporal resolution, continuously improving spatial density, and less expensive receivers, ground-based GPS networks have been identified as a useful technique to monitor long term variations in the IWV [2].

T. Ning and G. Elgered are with the Department of Earth and Space Sciences, Chalmers University of Technology, Onsala Space Observatory, SE-43992, Onsala, Sweden (e-mail: tong.ning@chalmers.se; gunnar.elgered@chalmers.se) 
The atmospheric water vapor content has been investigated over long time scales using ground-based GPS networks, e.g. [3]. The potential capability of using GPS data to monitor climate changes (e.g. as a linear trend in the IWV) has been reported by many studies [4], [5], [6], [7]. In the region of this study, Gradinarsky et al. [8] used data from 1993 to 2002, and found positive IWV trends in general. Another study for the same area, but for the time period from 1996 to 2006 was carried out by Nilsson and Elgered [9]. They found IWV trends in the range from -0.5 to $+1.0 \mathrm{~kg} /\left(\mathrm{m}^{2}\right.$. decade), where the estimated uncertainties of the trends are dominated by the true variability of the IWV.

The accuracy of the GPS-derived IWV is affected by elevation-angle-dependent errors. They can be caused by atmospheric mapping functions [10], antenna phase center variations (PCV) [11], and signal multipath, including scattering [12]. Fang et al. [13] found that using the Niell Mapping Functions (NMF) [14] and including a model for the correction of the antenna PCV can significantly reduce systematic errors in the derived water vapor content. The multipath effects can be seen when we plot the GPS carrier phase postfit residuals against the elevation and azimuth angles [15]. For IWV trend estimates, systematic errors would be insignificant if they were constant over the whole time series. However, this is not always true since the signal multipath is also sensitive to the surrounding environment which reflective properties may change, e.g. caused by growing vegetation [16] and/or different soil moisture [17]. The multipath effects can to a large extent be removed by implementing microwave absorbing material below the GPS antenna plane [18]. They are worse for observations at low elevation angles, which are included in order to improve the geometry and reduce the formal error of the individual IWV estimate. Higher elevation cutoff angles may be desired for the IWV trend estimation due to the fact that the formal error of the IWV is not the limiting factor for this application [9].

Based on this, we investigated the impact of using different elevation cutoff angles thereby assessing possible elevation-angle-dependent systematic errors. In Section II, we describe the GPS data together with radiosonde observations, from nearby sites, that were used to infer time series of the IWV. A comparison between the IWV from the two techniques is presented in Section III. The estimation of trends and their uncertainties are discussed in Section IV. Section V presents the correlation between trends estimated from the GPS data for different elevation cutoff angles and trends from the radiosonde data. The impact of interventions at a site on the trend estimation is discussed in Section VI. Section VII contains the conclusions.

\section{DATA SET AND ANALYSIS}

Observations acquired from 12 GPS and 7 radiosonde sites in Sweden and Finland (Fig. 1), covering a time period of 14 years (Jan. 1997 to Dec. 2010), were used to estimate the IWV. The GPS data were analyzed by the GIPSY/OASIS II software (v. 5.0) [19] using the precise point positioning (PPP) strategy [20]. We used an a priori zenith hydrostatic delay (ZHD) from the model presented by Saastamoinen [21] (around $2.3 \mathrm{~m}$ depending on the height of the GPS site) and an a priori value of $100 \mathrm{~mm}$ for the zenith wet delay (ZWD) as the model for the zenith total delay (ZTD). Corrections for this a priori ZTD together with the horizontal delay gradients were estimated for 8 different elevation cutoff angles varying from $5^{\circ}$ to $40^{\circ}$. We did not apply any elevation- 
angle-dependent weighting of the observations. The NMFs were used [14]. The true ZHD was then calculated using the ground pressure given by the reanalysis product of the European Centre for Medium-Range Weather Forecasts (ECMWF) (http://www.ecmwf.int/research/era/do/get/Reanalysis_ECMWF). The pressure shows a rootmean-square (RMS) error of $0.6 \mathrm{hPa}$ (corresponding to $1.4 \mathrm{~mm}$ in the ZHD) when compared to ground pressure observations available at the ONSA site. The ZWD were obtained by subtracting the calculated ZHD from the estimated ZTD. The temporal resolution of the ZWD was $5 \mathrm{~min}$. The absolute calibrations of the PCV [11] were implemented for both satellite and ground antennas.

The ZWD can be related to the atmospheric IWV via a parameter $Q$ :

$$
Q=\frac{Z W D}{I W V} \approx \frac{3.754 \cdot 10^{-3} \int_{0}^{\infty} \frac{e(h)}{T(h)^{2}} d h}{\int_{0}^{\infty} \rho_{v}(h) d h}=\frac{3.754 \cdot 10^{-3} R_{w} \int_{0}^{\infty} \frac{e(h)}{T(h)^{2}} d h}{\int_{0}^{\infty} \frac{e(h)}{T(h)} d h}
$$

where $e(h)$ is the height profile of the partial pressure of water vapor; $T(h)$ is the temperature; $\rho_{v}$ is the absolute humidity in $\mathrm{kg} / \mathrm{m}^{3}$, which is proportional to $e / T$ (according to the ideal gas law). The constant $3.754 \cdot 10^{-3}$ has the unit of $\mathrm{K}^{2} \cdot \mathrm{m}^{2} / \mathrm{N} ; R_{w}$ is the specific gas constant for water vapor $(461.525 \pm 0.003 \mathrm{~N} \cdot \mathrm{m} /(\mathrm{kg} \cdot \mathrm{K}))$. A model depending on the latitude of the site and the day of the year was used to model the temperature dependence of $Q$ with an RMS uncertainty of less than $2 \%$ [22].

Radiosonde observations provide vertical profiles of pressure, temperature, and humidity. We linearly interpolated those profiles up to $12 \mathrm{~km}$ at intervals of $50 \mathrm{~m}$, and integrated the absolute humidity to calculate the IWV. Two different types of Vaisala radiosondes were used: first RS80 and then RS92. For all sites there was a transition period from late 2005 to early 2006 during which both types were used (personal communication: I. Hedenvik, Swedish Meteorological and Hydrological Institute, 28 June 2011 and Vaisala helpdesk, 11 July 2011). The specifications from the manufacturer state that the RS80 has a reproducibility of better than $3 \%$ (one standard deviation in the relative humidity) and an additional $2 \%$ uncertainty from the calibration. Assuming that they are independent errors results in a root-sum-squared value of $3.6 \%$ for the total uncertainty. The corresponding numbers for the RS92 are $2 \%$ and $1 \%$, resulting in a total uncertainty of $2.2 \%$. The assumption of normally distributed independent errors is likely optimistic. In the following we assign the calculated IWV an uncertainty of $4 \%$ (one standard deviation). Validation of the radiosonde observations has been carried out by many studies. Wang and Zhang [3] found a dry bias in the humidity measurements introduced by both Vaisala instruments and Niell et al. [23] also reported that radiosondes underestimated the ZWD (around $6 \mathrm{~mm}$ ) with respective to the ZWD obtained from a water vapor radiometer.

Due to the different temporal resolutions, the GPS data were interpolated to the radiosonde epochs using a Gaussian window, with a full width at half maximum, varying from 30 to 360 min depending on the distance between the paired sites [24]. 


\section{IWV COMPARISON}

Comparisons of IWV estimates obtained from 14 years of the GPS and the radiosonde data are shown in Fig. 2. Note that a radiosonde site can be compared to multiple GPS sites. The paired sites for each comparison are found in Table II. Fig. 2a depicts variations in the mean IWV difference for different elevation cutoff angles. The smallest variations are seen for the sites TUOR and METS, which are the only two GPS sites without radomes on the antenna [25]. An investigation on the impact of radomes is found in Emardson et al. [26]. Fig. 2b to 2d depict the standard deviation of the IWV difference for the summer, the winter, and all the data. Larger values are seen for KIVE and SODA in the winter season, which may be explained by the accumulation of snow and ice on the radome during the winter [27]. As expected, the standard deviation becomes larger as the elevation cutoff angle increases, when data are removed from the analysis and the geometry becomes weaker.

Although the differences are very small for some sites (of the order of $0.01 \mathrm{~kg} / \mathrm{m}^{2}$ ), the smallest RMS difference (see Fig. 2e) is obtained for the $10^{\circ}$ solution at the sites: SODA, SUN0, TUOR, METS, SKE0, VAN0, and OLKI. The sites VISO, ONSA, KIVE, and OVE0 have the smallest RMS difference for the $15^{\circ}$ solution, and at JONO it is obtained for the $20^{\circ}$ solution.

The ratios of the number of observations at each elevation cutoff angle to the number of total observations, and the corresponding formal uncertainty of the estimated IWV are shown in Fig. 3a and 3b, respectively. The number of observations drops below $50 \%$ when the elevation cutoff angle is higher than $25^{\circ}$, and the formal uncertainties increase approximately from $0.3 \mathrm{~kg} / \mathrm{m}^{2}$ for the $5^{\circ}$ solution up to $5 \mathrm{~kg} / \mathrm{m}^{2}$ for the $40^{\circ}$ solution.

\section{TREND ESTIMATION}

Linear trends in the IWV were estimated from the GPS and the radiosonde data using the model [9]:

$$
\begin{aligned}
y= & y_{0}+a_{1} t+a_{2} \sin (2 \pi t)+a_{3} \cos (2 \pi t) \\
& +a_{4} \sin (4 \pi t)+a_{5} \cos (4 \pi t)
\end{aligned}
$$

where $y$ and $t$ are the IWV and the time in years (from 1 Jan. 1997 at UTC 0:00), respectively. The parameters $y_{0}$ and $a_{1}$ are the mean and the linear trend of the IWV, respectively; $a_{2}$ and $a_{3}$ are the annual component coefficients, and $a_{4}$ and $a_{5}$ are the semi-annual component coefficients. All unknown coefficients are determined through the method of least squares.

A complication in the trend estimation is that changes during the operation of a GPS or a radiosonde site may cause systematic effects in the time series which may change the trend [28]. In our data set, the GPS site ONSA had a radome change on 1 Feb. 1999, which may introduce an offset in the IWV time series. The magnitude of the offset can be determined from the IWV comparison between the GPS data set and the one acquired from a co-located technique which is homogeneous. For the ONSA site, this was done (for each elevation cutoff angle) by comparing the GPS-derived IWV to the IWV estimated from Very Long Baseline Interferometry (VLBI) data, which were acquired $78 \mathrm{~m}$ away from the GPS site [24]. The IWV trend for ONSA was then estimated after applying an offset correction for the time period before the change of the radome. Note that we did not correct 
for the offset due to the change of the sensor when estimating IWV trends for all radiosonde sites. This will be discussed in Section VI.

Before comparing the trends from the GPS and the radiosonde data the meaning of uncertainties is discussed. The estimated linear trends have rather large uncertainties caused by the true short term variation (the natural variability of the weather) which are not described by the model. This phenomena means that trends, as well as their uncertainties, are typically larger for short time periods, and as time periods become longer both parameter values will decrease. In order to calculate the trend uncertainty after taking these short term variation into account, we used a model which was presented by Nilsson and Elgered [9]:

$$
\operatorname{Cov}\left[V_{1}\left(t_{1}\right), V_{2}\left(t_{2}\right)\right]=a_{1} 2^{-\left|t_{1}-t_{2}\right| / T_{1}}+a_{2} 2^{-\left|t_{1}-t_{2}\right| / T_{2}}
$$

where $V_{1}$ and $V_{2}$ are IWV values observed at the time epochs $t_{1}$ and $t_{2}$, respectively. The coefficients $a_{1}, a_{2}, T_{1}$, and $T_{2}$ can be obtained by a fit to the covariance, which is calculated from the residuals after the fit of the IWV to the model (Equation 2). From the covariance model, the covariance matrix for the observations can be computed for the estimation of the trend uncertainties. The resulting uncertainties are shown in Fig. 4a.

However, when comparing trends from the GPS and the radiosonde data acquired during the same time period - and weather conditions - the expected differences should be significantly smaller. In order to estimate the lower bound of these we used the formal uncertainties of both the radiosonde (assumed to be $4 \%$ of the absolute value, see Section II) and the individual GPS estimates shown in Fig. $3 \mathrm{~b}$ for the calculation of the trend uncertainty and assuming that the residuals after the model fit (Equation 2) are described by white noise. The radiosonde trend uncertainty is then $0.015 \mathrm{~kg} /\left(\mathrm{m}^{2} \cdot \mathrm{decade}\right)$ and the elevation-angle-dependent GPS uncertainty varies from $0.01 \mathrm{~kg} /\left(\mathrm{m}^{2} \cdot\right.$ decade) at $5^{\circ}$ to $0.2 \mathrm{~kg} /\left(\mathrm{m}^{2} \cdot\right.$ decade) at $40^{\circ}$ (see Fig. $\left.4 \mathrm{~b}\right)$. Excluding the highest cutoff angles, these uncertainties are very small, but note that no systematic errors have yet been taken into account. Examples of such errors are changes in the radiosonde sensor type, calibration equipment, and the electromagnetic environment, including the horizon mask of a GPS site. This will be discussed later in Section VI.

\section{RESULTS: ESTIMATED TRENDS}

Because of the large variability in the IWV the estimated trends are sensitive to gaps if there are periods without data. A synchronization of the two data sets being compared is therefore necessary [29]. For each comparison, this was done by using the GPS data acquired simultaneous to launches from the radiosonde site. Fig. 5 depicts correlations of the IWV trends obtained from the radiosonde data to the ones given by the GPS data for the 8 different elevation cutoff angles. It is evident that the correlation varies for different angles. The highest correlation coefficient of 0.88 is seen for the $25^{\circ}$ solution. The larger differences seen for the solutions at lower elevation angles may be explained by elevation-angle-dependent errors, where signal multipath, including scattering, is the major contributor. Above $25^{\circ}$ the IWV estimates suffer from less data $(<50 \%$ of all observations) and a weaken geometry, which also affects the formal uncertainties (Fig. 3b). The results in Fig. 5 are also presented in Table I. We note that the RMS difference between the estimated trends only show a small variability for cutoff angles up to $25^{\circ}$, where the best agreement is obtained, but increase significantly for higher cutoff angles. 
Further details of the $25^{\circ}$ solution are shown in Table II. As already seen in Fig. 2 the RMS difference increases as the distance between the paired GPS and radiosonde sites gets larger due to the true spatial IWV difference. This is, however, not necessarily seen in the trend comparison due to the fact that the size of trends is comparable to the uncertainty.

Another issue worth studying is the possible influence of different mapping functions since they have an elevationangle-dependent effect. However, we do not expect a strong time dependence over time scales of many years. We investigated the impact of using also the Vienna mapping functions [30] for the Onsala GPS data. The largest difference in the IWV trend of $0.05 \mathrm{~kg} /\left(\mathrm{m}^{2}\right.$.decade) is obtained for the $5^{\circ}$ solution. We therefore conclude that the choice of mapping functions is not critical for this specific study.

\section{DISCUSSION ON INTERVENTIONS}

We define an intervention as a specific change related to an instrument or measurement technique. An intervention may introduce an offset in the resulting time series from the date of the intervention. An intervention is often motivated by a wish to improve the accuracy. It is, therefore, more appropriate to view it as a removal, or at least a reduction of a previously existing offset. When estimating a linear trend from a time series including interventions there are three possible choices: (i) ignore the intervention, (ii) apply a correction obtained from an independent source of information to the data acquired before the intervention, and (iii) estimate the size of the correction at the time epoch of the intervention assuming a constant trend over the entire time period.

For the latter case the uncertainty of the estimated IWV trend will increase depending on when the intervention occurs. The worst scenario is to have the intervention in the middle of the time series which implies that the uncertainty increases by a factor of 2 [31]. This is a useful method if no other information exist and is often used for coordinate time series describing e.g. tectonic plate motion and land uplift when there are strong evidence that the trend is the same before and after the intervention. For our application of estimating trends in the IWV there are on the contrary no evidence that the trends shall be constant over many years due to the large variability in the weather.

\section{A. Interventions in GPS data}

In our case, an intervention occurred at ONSA on 1 Feb. 1999 when the radome protecting the antenna was changed. Using the three methods mentioned above we obtain the following results for the $25^{\circ}$ elevation cutoff angle solution: (i) ignoring the intervention implies a trend of $-1.16 \mathrm{~kg} /\left(\mathrm{m}^{2} \cdot \mathrm{decade}\right)$; (ii) applying an offset of $-1.18 \mathrm{~kg} / \mathrm{m}^{2}$ to the IWV data before the intervention implies a trend of $-0.25 \mathrm{~kg} /\left(\mathrm{m}^{2} \cdot\right.$ decade $)$; this correction is obtained from comparisons to VLBI data acquired at the Onsala site over the entire time period [24]; (iii) trying to estimate the size of the intervention from the IWV data themselves results in an offset of $-0.73 \mathrm{~kg} / \mathrm{m}^{2}$ and a trend of $-0.6 \mathrm{~kg} /\left(\mathrm{m}^{2} \cdot\right.$ decade $)$ which confirms that the IWV trend is not constant over the time period.

Referring to the discussion above we used the second method for the ONSA site. We note that if the independent VLBI data had not been available, meaning that also the offset value must be estimated or ignored, the resulting 
trends are significantly different and most likely also less accurate. In fact we have GPS data from another site, SPT0, $36 \mathrm{~km}$ east of Landvetter, where no other technique is available to correct for an intervention of adding a microwave absorber below the antenna on 9 Jun. 2007. Therefore data from this site were not included.

There may also be slow changes of the electromagnetic environment around the GPS antenna, that cannot be characterized as an intervention at a specific time epoch, which affects the signal multipath. At some sites, such as VIS0, METS, and SKE0, the differences between the radiosonde and GPS-derived IWV trends are similar for the elevation cutoff angles from $5^{\circ}$ to $25^{\circ}$ (see Table II and Fig. 2). However, for some sites, the multipath effects seem not to be stable with time. For example, growing vegetation and different soil moisture may change the pattern of the signal multipath for different elevation angles. Identification of such changes is difficult, and requires careful and continuous documentation of each site. Such investigations are important for future studies.

\section{B. Interventions in radiosonde data}

All radiosonde sites changed the type of sensor late in 2005 and early in 2006. For simplicity, we assumed the same date (1 Feb. 2006) for the change for all radiosonde sites. We tried to obtain the magnitude of the offset due to the intervention using the IWV comparison from the pair of radiosonde and GPS sites with the shortest distance: Visby-VIS0. Comparing the radiosonde IWV to the GPS IWV for three elevation cutoff angles $\left(10^{\circ}, 15^{\circ}\right.$ and $\left.20^{\circ}\right)$ give a similar value for the offset of $0.1 \mathrm{~kg} / \mathrm{m}^{2}$. However, this value is not completely reliable since the uncertainty of the radiosonde-derived IWV is specified as a percentage of the absolute value, the offset due to the change of instrument will alias with the offset due to different weather conditions before and after the intervention. In order to investigate the impact of ignoring the intervention on the estimated radiosonde IWV trend and on the resulting correlation, we carried out a test by applying different offsets (from 0.1 to $0.5 \mathrm{~kg} / \mathrm{m}^{2}$ ) to the IWV before 1 Feb. 2006. The upper limit value of the offset was taken from the result given by Wang and Zhang [3], where a wet offset of approximately $0.5 \mathrm{~kg} / \mathrm{m}^{2}$ in IWV from RS92 with respect to RS80 was reported. Fig 6 depicts the difference between the radiosonde IWV trend after corrections for 5 different offsets and the one without any offset correction. The variation in the trend difference for a certain offset, from 0.02 to $0.1 \mathrm{~kg} /\left(\mathrm{m}^{2} \cdot\right.$ decade), slightly increases as the magnitude of the offset becomes larger. The resulting correlation coefficients between the IWV trends from the radiosonde and the GPS data for different cutoff angles are shown in Fig 7. Based on this, we decided not to correct the offset when estimating IWV trends for the radiosonde sites.

\section{CONCLUSIONS}

We have used 14 years of observations from 12 GPS and 7 radiosonde sites in Sweden and Finland to estimate the IWV. The GPS data were processed using 8 different elevation cutoff angles varying from $5^{\circ}$ to $40^{\circ}$. The best agreement in the IWV trends is obtained for the $25^{\circ}$ solution with a correlation coefficient of 0.88 . This is different from the optimum cutoff angle obtained when identifying the smallest RMS difference for the IWV time series between a GPS and a radiosonde site which is typically $10^{\circ}$ and $15^{\circ}$. 
We conclude that the optimum elevation cutoff angle depends on the application. It is a balance between high accuracy of individual IWV estimates and the sensitivity to time dependent systematic errors. A high elevation cutoff angle implies a poor geometry and a larger uncertainty in the individual IWV estimates but at the same time they reduce the impact of systematic (time-dependent) errors that tend to increase at low elevation angles, e.g. signal multipath.

The estimated trends are small. For all sites at the optimum elevation cutoff angle $\left(25^{\circ}\right)$ they are between -0.78 and $+0.66 \mathrm{~kg} /\left(\mathrm{m}^{2} \cdot\right.$ decade) (Table II). Given that the formal uncertainty is $0.45 \mathrm{~kg} /\left(\mathrm{m}^{2} \cdot\right.$ decade) we cannot claim to have detected a trend at any specific site. However, given that we have a correlation between trends from the two completely independent techniques we have strong evidence that the two techniques measure the IWV variability correctly although the true trends in the studied area and time period are too small to be uniquely detected.

It is important to carry out similar studies for other sites and especially from areas with different climates. Furthermore, the optimum cutoff angle $\left(25^{\circ}\right)$ for the trend estimation may be different for GPS sites in different electromagnetic environments and sites at lower latitudes, where the distribution of observations as a function of elevation angle is different.

\section{ACKNOWLEDGMENT}

This research is supported by VINNOVA, the Swedish Governmental Agency for Innovation Systems, through the project P29459-1 "Long Term Water Vapour Measurements Using GPS for Improvement of Climate Modelling”. The map in Fig. 1 was produced using the Generic Mapping Tools [32].

\section{REFERENCES}

[1] S. A. Buehler, A. von Engeln, E. Brocard, V. O. John, T. Kuhn, and P. Eriksson, "Recent developments in the line-by-line modeling of outgoing longwave radiation,” J. Quant. Spectrosc. Radiat. Transfer, vol. 98, no. 12, pp. 446-457, doi:10.1016/j.jqsrt.2005.11.001, 2006.

[2] S. Businger, S. R. Chiswell, M. Bevis, J. Duan, R. A. Anthes, C. Rocken, R. H. Ware, M. Exner, T. VanHove, and F. S. Solheim, "The promise of GPS in atmospheric monitoring," Bull. Am. Meteorol. Soc., vol. 77, no. 1, pp. 5-18, doi: 10.1175/15200477(1996)077<0005:TPOGIA >2.0.CO;2, 1996.

[3] J. Wang, and L. Zhang, "Systematic errors in global radiosonde precipitable water data from comparisons with ground-based GPS measurements," J. Clim., vol. 21, no. 10, pp. 2218-2238, doi:10.1175/2007JCLI1944.1, 2008.

[4] J. Morland, M. Collaud Coen, K. Hocke, P. Jeannet, and C. Mätzler, "Tropospheric water vapour above Switzerland over the last 12 years," Atmos. Chem. Phys., vol. 9, no. 2, pp. 7239-7271, doi:10.5194/acpd-9-7239-2009, 2009.

[5] S. Heise, G. Dick, G. Gendt, T. Schmidt, and J. Wickert, "Integrated water vapor from IGS ground-based GPS observations: initial results from a global 5-min data set," Ann. Geophys., vol. 27, no. 7, pp. 2851-2859, doi:10.5194/angeo-27-2851-2009, 2009.

[6] D-H, Sohn, and J. Cho, "Trend Analysis of GPS Precipitable Water Vapor Above South Korea Over the Last 10 years," J. Astron. Space Sci., vol. 27, no. 3, pp. 231-238, doi: 10.5140/JASS.2010.27.3.231, 2010.

[7] S. G. Jin, and O. F. Luo, "Variability and Climatology of PWV From Clobal 13-Year GPS observations," IEEE Geosci. Rem. Sens., vol. 47, no. 7, pp. 1918-1924, doi: 10.1109/TGRS.2008.2010401, 2009.

[8] L. P. Gradinarsky, J. Johansson, H. R. Bouma, H. G. Scherneck, and G. Elgered, "Climate monitoring using GPS," Phys. Chem. Earth, vol. 27, no. 4, pp. 335-340, doi:10.1016/S1474-7065(02)00009-8, 2002.

[9] T. Nilsson and G. Elgered, "Long-term trends in the atmospheric water vapor content estimated from ground-based GPS data," J. Geophys. Res., vol. 113, no. D19, pp. D19101, doi:10. 1029/2008JD010110, 2008. 
[10] B. Stoew, T. Nilsson, G. Elgered, and P. O. J. Jarlemark, "Temporal correlations of atmospheric mapping function errors in GPS estimation," J. Geod., Vol. 81, no. 5, pp. 311-323, doi: 10.1007/s00190-006-0114-0, 2007.

[11] R. Schmid, P. Steigenberger, G. Gendt, M. Ge, and M. Rothacher, "Generation of a consistent absolute phase center correction model for GPS receiver and satellite antennas," J. Geod., vol. 81, no. 12, pp. 781-798, doi:10.1007/s00190-007-0148-y, 2007.

[12] P. Elósegui, J. L. Davis, R. T. K. Jaldehag, J. M. Johansson, A. E. Niell, and I. I. Shapiro, "Geodesy using the Global Positioning System: the effects of signal scattering on estimates of site position,” J. Geophys. Res., vol. 100, no. B6, pp. 9921-9934, doi:10.1029/95JB00868, 1995.

[13] P. Fang, M. Bevis, Y. Bock, S. Gutman, and D. Wolfe, "GPS meteorology: Reducing systematic errors in geodetic estimates for zenith delay," Geophys. Res. Lett., vol. 25, no. 19, pp. 3583-3586, doi:10.1029/98GL02755, 1998.

[14] A. E. Niell, "Global mapping functions for the atmosphere delay at radio wavelengths," J. Geophys. Res., vol. 101, no. B2, pp. 3227-3246, doi:10.1029/95JB03048, 1996.

[15] Y. Shoji, H. Nakamura, T. Iwabuchi, K. Aonashi, H. Seko, K. Mishima, A. Itagaki, R. Ichikawa, and R. Ohtani, "Tsukuba GPS Dense Net Campaign Observation: Improvement in GPS Analysis of Slant Path Delay by Stacking One-way Postfit Phase Residuals," J. Meteor. Soc. Japan, Vol. 82, no. 1B, pp. 301-314, 2004.

[16] C. Granström, and J. Johansson, "The Influence of Vegetation and Multipath on GNSS signals," in proc. Radio Science and Communication, Linköping, Sweden, June 14-16, pp. 385-390, 2005.

[17] K. M. Larson, J. J. Braun, E. E. Small, V. U. Zavorotny, E. D. Gutmann, and A. L. Bilich, "GPS Multipath and Its Relation to Near-Surface Soil Moisture Content," IEEE J-STARS, vol. 3, no. 1, pp. 91-99, 10.1109/JSTARS.2009.2033612 , 2010.

[18] T. Ning, G. Elgered, and J.M. Johansson, "The impact of microwave absorber and radome geometries on GNSS measurements of station coordinates and atmospheric water vapour," Adv. Space. Res., vol. 47, no. 2, pp. 186-196, doi:10.1016/j.asr.2010.06.023, 2011.

[19] F. H. Webb and J. F. Zumberge, "An introduction to the GIPSY/OASIS-II," JPL Publ., no. D-11088, Jet Propulsion Laboratory, Pasadena, California, 1993.

[20] J. F. Zumberge, M. B. Heflin, D. C. Jefferson, M. M. Watkins, and F. H. Webb, "Precise point positioning for the efficient and robust analysis of GPS data from large networks," J. Geophys. Res., vol. 102, no. B3, pp. 5005-5017, doi:10.1029/96JB03860, 1997.

[21] J. Saastamoinen, "Contributions to the theory of atmospheric refraction,” Bull Géod, vol. 107, no. 1, pp. 13-34, doi: 10.1007/BF02521844, 1973.

[22] T. R. Emardson and H. J. P. Derks, "On the relation between the wet delay and the integrated precipitable water vapor in the European atmosphere," Meteorol. Appl., vol. 7, no. 1, pp. 61-68, doi:10.1017/S1350482700001377, 2000.

[23] A. E. Niell, A. J. Coster, F. S. Solheim, V. B. Mendes, P. C. Toor, R. B. Langley, C. A. Upham, "Comparison of measurements of atmospheric wet delay by radiosonde, water vapor radiometer, GPS, and VLBI", J. Atmos. Oceanic. Technol., vol. 18, no. 6, pp. 830-850, doi:10.1175/1520-0426(2001)018<0830:COMOAW>2.0.CO:2, 2001.

[24] T. Ning, R. Haas, G. Elgered, and U. Willén, "Multi-technique comparisons of ten years of wet delay estimates on the west coast of Sweden," J. Geod., accepted, doi: 10.1007/s00190-011-0527-2, 2011.

[25] H. Koivula, "Implementation and prospects for use of a high precision geodetic GPS monitoring network (Finnref) covering Finland," Licentiate thesis, Department of Surveying, Helsinki University of Technology, 2006.

[26] T. R. Emardson, J. M. Johansson, and G. Elgered, "The systematic behavior of water vapor estimates using four years of GPS observations," Trans. IEEE Geosci. Remote Sens., vol. 38, no. 1, pp. 324-329, doi:10.1109/36.823927, 2000.

[27] J. M. Johansson, J. L. Davis, H. G. Scherneck, G. A. Milne, M. Vermeer, J. X. Mitrovica, R. A. Bennett, B. Jonsson, G. Elgered, P. Elóegui, H. Koivula, M. Poutanen, B. O. Rönnög, and I. I. Shapiro, “Continuous gps measurements of postglacial adjustment in Fennoscandia 1. Geodetic results," J. Geophys. Res., vol. 107, no. B8, doi:10.1029/2001JB000400, 2002.

[28] J. Campbell, "European vertical site motions by VLBI and GPS an update," Proc. of the 16'th Working Meeting on European VLBI for Geodesy and Astrometry, Bundesamt Für Kartographie und Geodäsie, pp. 267-278, 2003.

[29] R. Haas, T. Ning, and G. Elgered, "Observation of long term trends in the amount of atmospheric water vapor by space geodesy and remote sensing techniques," Proc. of IEEE International Geoscience and Remote Sensing Symposium, Honolulu, Hawaii, U.S.A., July 25-30, pp. 2944-2947, doi:10.1109/IGARSS.2010.5649040, 2010.

[30] J. Boehm, B. Werl, and H. Schuh, “Troposphere mapping functions for GPS and very long baseline interferometry from European Centre for 
Medium-Range Weather Forecasts operational analysis data," J. Geophys. Res., vol. 111, no. B02, pp. B02406, doi:10.1029/2005JB003629, 2006.

[31] E. C. Weatherhead, G. G. Reinsel, G. C. Tiao, X-L. Meng, D. Choi, W-K. Cheang, T. Keller, J. DeLuisi, D. J. Wuebbles, J. B. Kerr, A. J. Miller, S. J. Oltmans, and J. E. Frederick, "Factors affecting the detection of trends: Statistical considerations and applications to environmental data," J. Geophys. Res., vol. 103, no. D14, pp. 17149-17161, doi:10.1029/98JD00995, 1998.

[32] P. Wessel and W. H. F. Smith, "New, improved version of generic mapping tools released," EOS Trans. Amer. Geophys. U., vol. 79, no. 47, pp. 579, doi:10.1029/98EO00426, 1998.

Tong Ning was born in GuiYang, China, in 1975. He received the M.Sc. degree in electronics/telecommunication from Gävle University, Gävle, Sweden, in 2007. He is currently pursuing a Ph.D. degree in electrical engineering at Chalmers University of Technology, Gothenburg, Sweden.

Gunnar Elgered was born in Götene, Sweden, in 1955. He received the M.S.E.E and Ph.D. degrees from Chalmers University of Technology, Gothenburg, Sweden, in 1977 and 1983, respectively. He is presently a Professor in electrical measurements and chairs the Department of Earth and Space Sciences at Chalmers. His research is focused on remote sensing of the atmosphere using space geodetic techniques and microwave radiometry. 


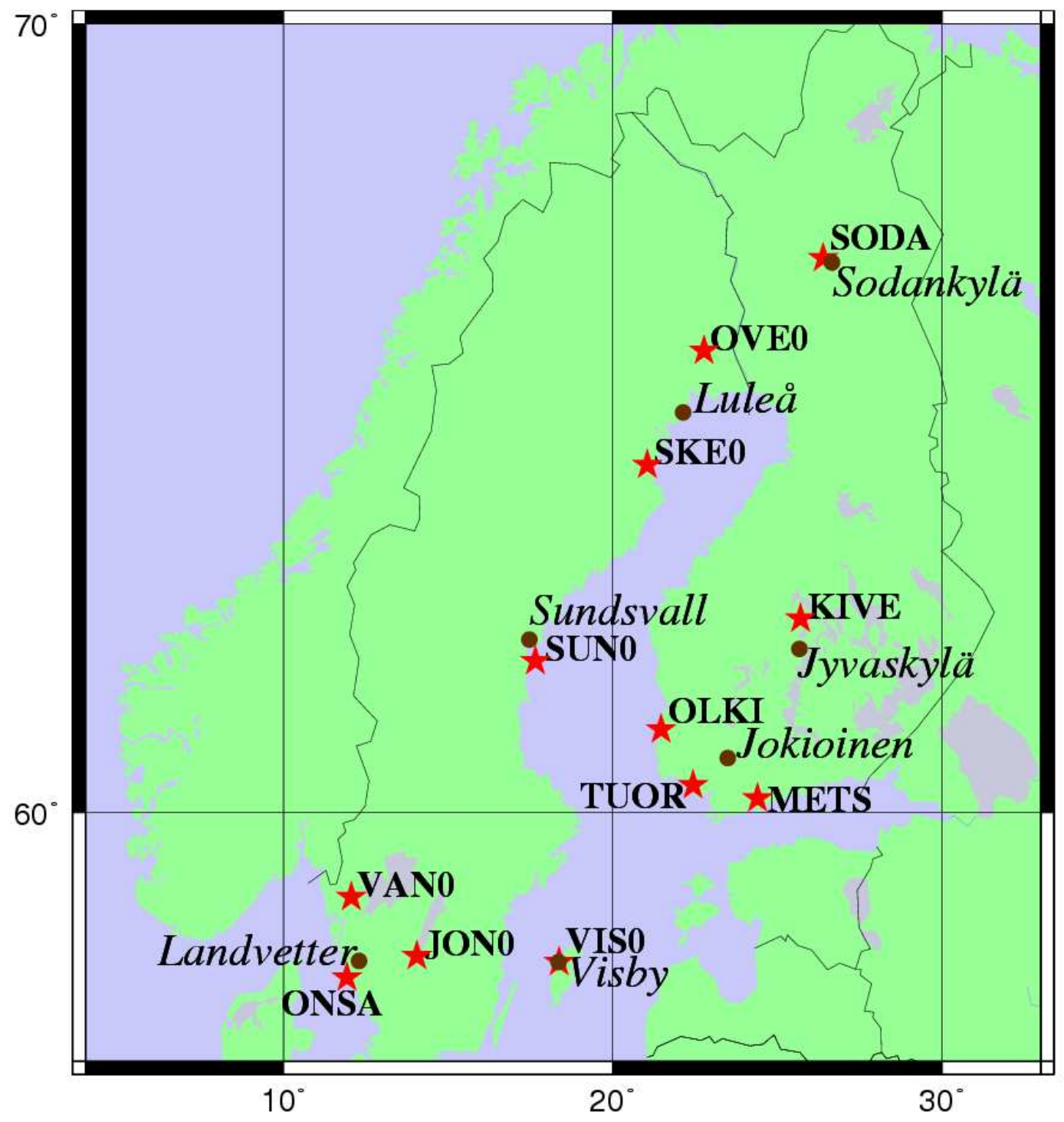

Fig. 1. The 12 GPS (stars) and the 7 radiosonde (dots) sites. 

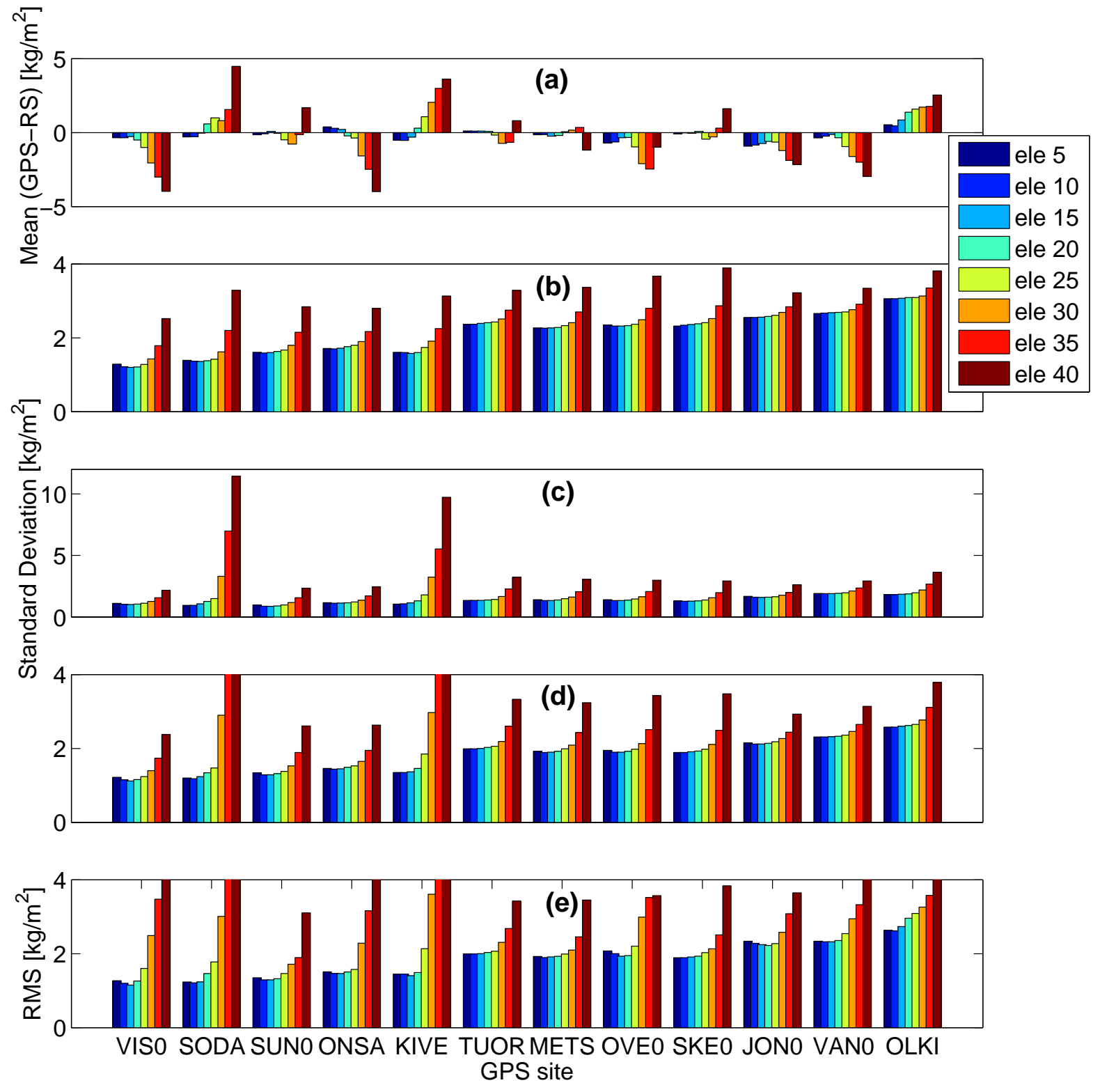

Fig. 2. (a) The mean, (b) the standard deviation for the summer seasons (April-September), (c) the standard deviation for the winter seasons (October-March), (d) the standard deviation for all the data, and (e) the RMS of the IWV differences from the comparisons between the GPS and the radiosonde (RS) data for 8 different elevation cutoff angles. Note that in order to increase the resolution, the scale of (d) and (e) was set to $4 \mathrm{~kg} / \mathrm{m}^{2}$. Therefore, a few values for the higher elevation cutoff angles cannot be seen. 


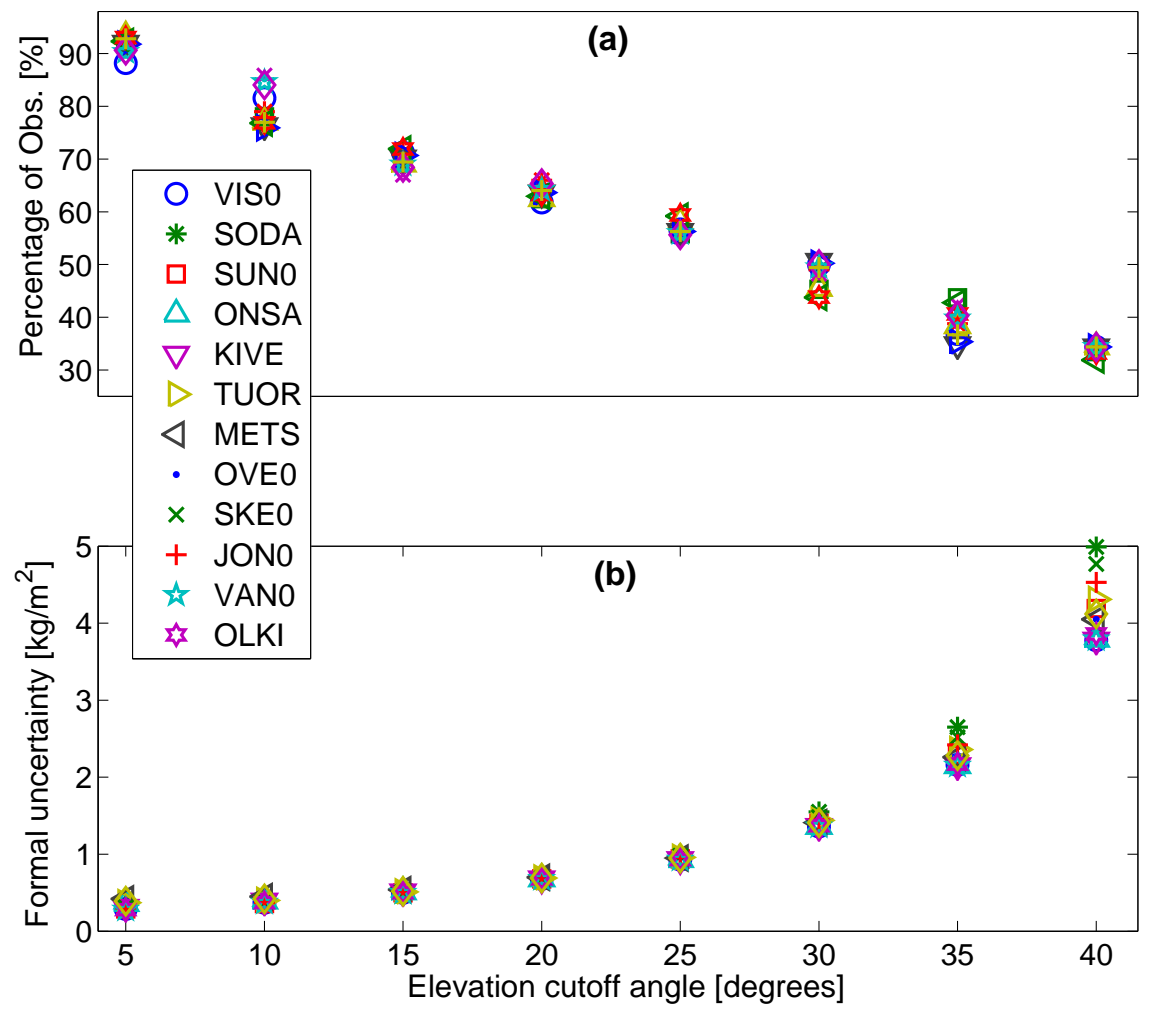

Fig. 3. (a) The percentage of observations used for each elevation cutoff angle with respect to the total number of observations for a typical $24 \mathrm{~h}$ period, and (b) the formal uncertainties of the IWV estimates given by the GIPSY processing. 


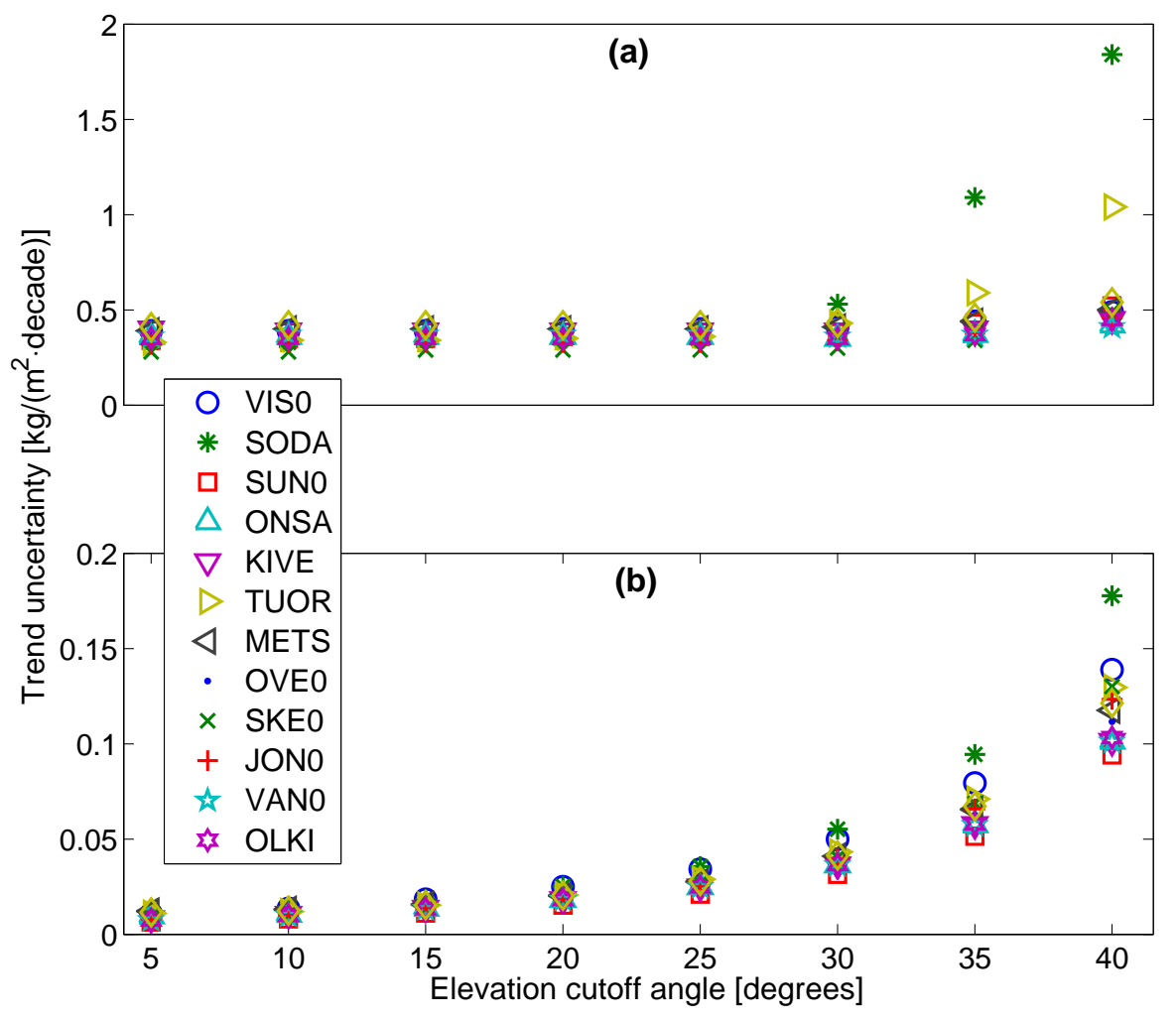

Fig. 4. The uncertainties of the IWV trends obtained (a) after rescaling and taking the short term temporal correlation of the IWV into account, and (b) by using the formal uncertainties (Fig. 3b) and assuming a white noise behavior.

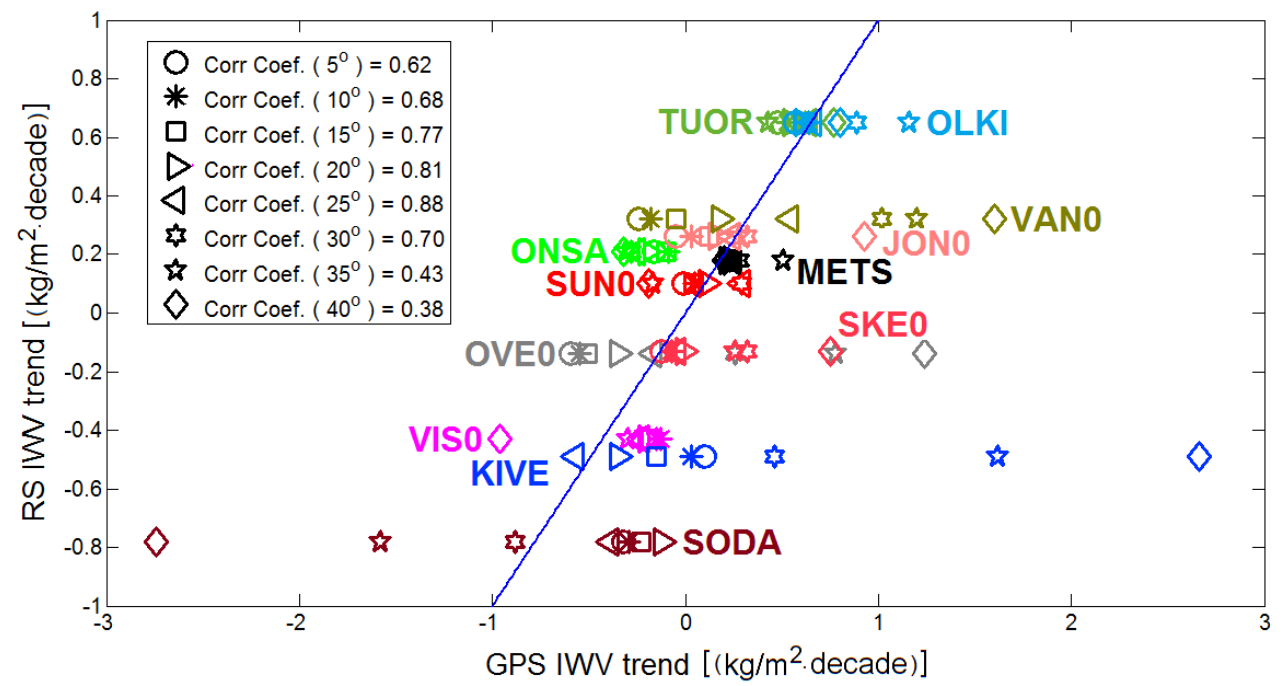

Fig. 5. Correlations between the IWV trends from the radiosonde and the GPS data for 8 different elevation cutoff angles. The solid line shows the perfect agreement. 


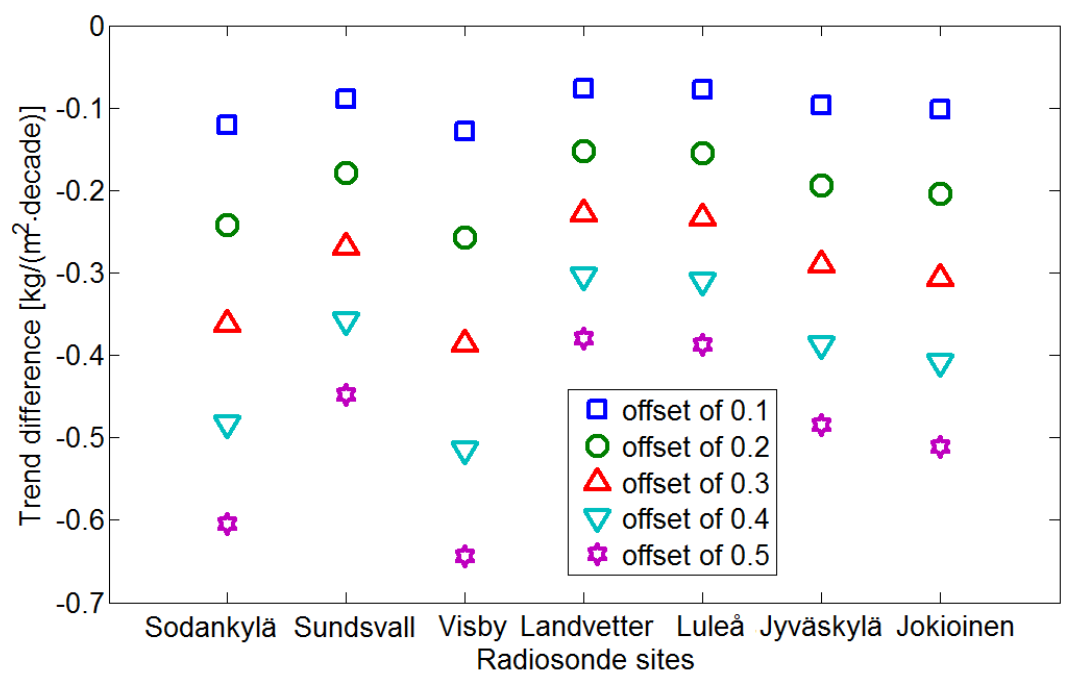

Fig. 6. Differences in the radiosonde-derived IWV trend after corrections for different offsets to the trend obtained without applying the offset correction.

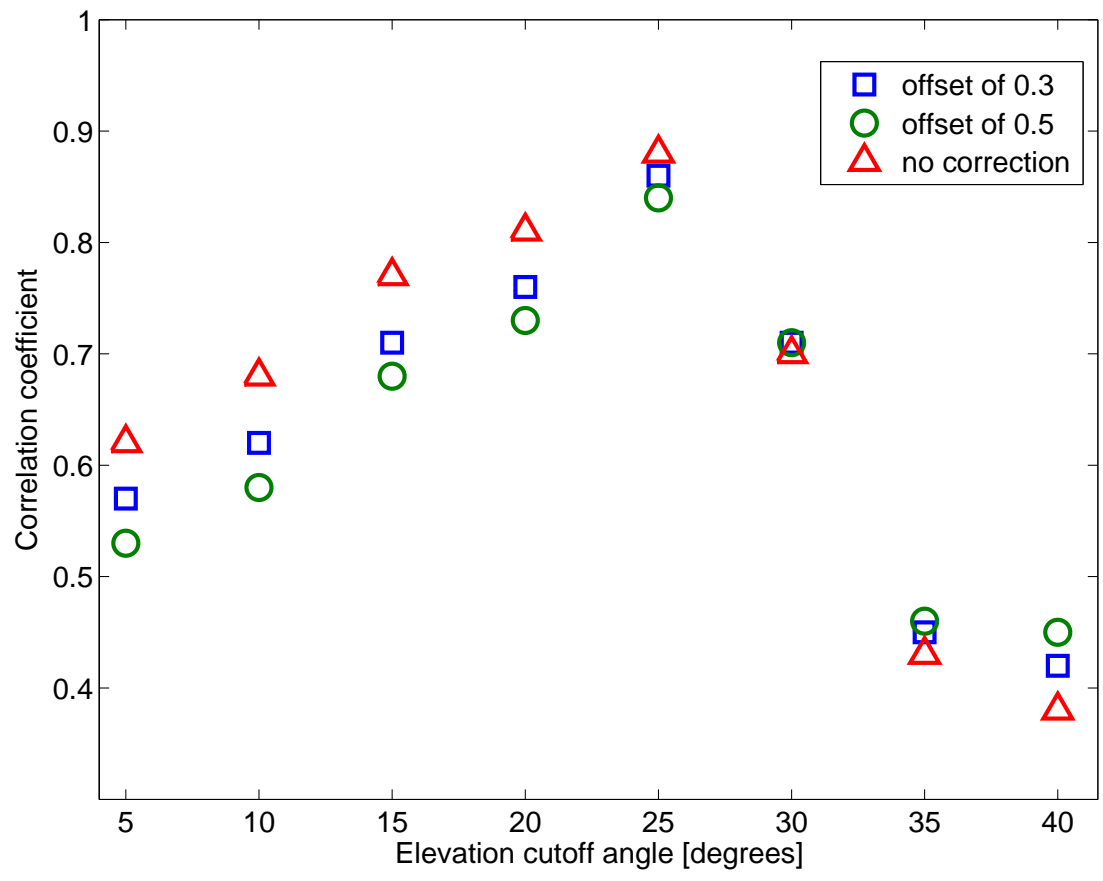

Fig. 7. Correlation coefficients between the IWV trends for 8 different elevation cutoff angles with and without applying corrections for offsets in the radiosonde data. 
TABLE I

THE STATISTICS OF THE DIFFERENCES OF THE IWV TRENDS BETWEEN THE RADIOSONDE AND THE GPS DATA OBTAINED FOR DIFFERENT ELEVATION CUTOFF ANGLES.

\begin{tabular}{l|rrrrrrrr}
\hline & \multicolumn{7}{c}{ GPS trend radiosonde trend $\left[\mathrm{kg} /\left(\mathrm{m}^{2} \cdot\right.\right.$ decade $\left.)\right]$} \\
Elevation Cutoff Angle & $5^{\circ}$ & $10^{\circ}$ & $15^{\circ}$ & $20^{\circ}$ & $25^{\circ}$ & $30^{\circ}$ & $35^{\circ}$ & $40^{\circ}$ \\
\hline \hline VIS0 & 0.21 & 0.33 & 0.28 & 0.25 & 0.19 & 0.31 & 0.16 & -0.50 \\
SODA & 0.46 & 0.49 & 0.55 & 0.66 & 0.39 & -0.10 & -0.80 & -1.96 \\
SUN0 & -0.11 & -0.05 & -0.06 & 0.01 & 0.19 & 0.19 & -0.27 & -0.29 \\
ONSA & -0.37 & -0.30 & -0.31 & -0.41 & -0.46 & -0.49 & -0.52 & -0.53 \\
KIVE & 0.59 & 0.52 & 0.34 & 0.14 & -0.08 & 0.95 & 2.11 & 3.15 \\
TUOR & -0.17 & -0.12 & -0.09 & -0.10 & -0.01 & -0.03 & -0.22 & 0.12 \\
METS & 0.03 & 0.05 & 0.06 & 0.04 & 0.06 & 0.10 & 0.33 & 0.02 \\
OVE0 & -0.45 & -0.41 & -0.37 & -0.21 & -0.03 & 0.40 & 0.92 & 1.38 \\
SKE0 & 0.01 & 0.06 & 0.08 & 0.12 & 0.09 & 0.45 & 0.39 & 0.88 \\
JON0 & -0.31 & -0.23 & -0.14 & -0.10 & -0.02 & 0.06 & 0.02 & 0.67 \\
VAN0 & -0.56 & -0.50 & -0.37 & -0.14 & 0.22 & 0.70 & 0.88 & 1.28 \\
OLKI & -0.08 & 0.01 & -0.04 & -0.04 & 0.01 & 0.24 & 0.51 & 0.15 \\
\hline RMS difference & 0.36 & 0.33 & 0.29 & 0.27 & 0.21 & 0.44 & 0.83 & 1.32 \\
Mean difference & -0.06 & -0.02 & -0.01 & 0.02 & 0.05 & 0.23 & 0.29 & 0.36 \\
Standard deviation & 0.35 & 0.33 & 0.28 & 0.26 & 0.21 & 0.38 & 0.78 & 1.27 \\
\hline
\end{tabular}

TABLE II

COMPARISONS OF THE IWV ESTIMATES BETWEEN RADIOSONDE (RS) RESULTS AND THE GPS RESULTS OBTAINED FORM THE SOLUTION USING A $25^{\circ}$ ELEVATION CUTOFF ANGLE.

\begin{tabular}{|c|c|c|c|c|c|c|c|c|}
\hline $\begin{array}{l}\text { GPS Site } \\
\text { Acronym }\end{array}$ & $\begin{array}{l}\text { Radiosonde } \\
\text { Site }\end{array}$ & $\begin{array}{l}\text { Distance } \\
{[\mathrm{km}]}\end{array}$ & $\begin{array}{c}\text { No. of } \\
\text { paired } \\
\text { obs. }\end{array}$ & $\begin{array}{r}\text { Mean } \\
\text { GPS IWV } \\
{\left[\mathrm{kg} / \mathrm{m}^{2}\right]}\end{array}$ & $\begin{array}{r}\text { GPS trend } \\
\text { (/decade) } \\
{\left[\mathrm{kg} / \mathrm{m}^{2}\right]}\end{array}$ & $\begin{array}{r}\text { RS trend }{ }^{1} \\
\text { (/decade) } \\
{\left[\mathrm{kg} / \mathrm{m}^{2}\right]}\end{array}$ & $\begin{array}{c}\text { Bias } \\
(\text { GPS-RS) } \\
{\left[\mathrm{kg} / \mathrm{m}^{2}\right]}\end{array}$ & $\begin{array}{r}\text { RMS } \\
{\left[\mathrm{kg} / \mathrm{m}^{2}\right]}\end{array}$ \\
\hline VIS0 & Visby & 1 & 6925 & 12.8 & -0.24 & -0.43 & -1.01 & 1.60 \\
\hline SODA & Sodankylä & 12 & 7049 & 11.7 & -0.39 & -0.78 & 1.00 & 1.78 \\
\hline SUNO & Sundsvall & 35 & 11142 & 12.1 & 0.29 & 0.10 & -0.49 & 1.46 \\
\hline ONSA & Landvetter & 37 & 9499 & 13.0 & -0.25 & 0.21 & -0.37 & 1.57 \\
\hline KIVE & Jyväskylä & 47 & 7385 & 12.6 & -0.57 & -0.49 & 1.01 & 2.11 \\
\hline TUOR & Jokioinen & 73 & 7616 & 12.8 & 0.64 & 0.65 & -0.19 & 2.05 \\
\hline METS & Jokioinen & 83 & 8185 & 12.8 & 0.24 & 0.18 & 0.06 & 1.99 \\
\hline OVE0 & Luleå & 90 & 8898 & 10.3 & -0.17 & -0.14 & -0.97 & 2.20 \\
\hline SKE0 & Luleå & 90 & 8925 & 10.8 & -0.04 & -0.13 & -0.44 & 2.02 \\
\hline JONO & Landvetter & 105 & 9556 & 12.8 & 0.24 & 0.26 & -0.64 & 2.27 \\
\hline VANO & Landvetter & 114 & 9496 & 12.5 & 0.54 & 0.32 & -0.95 & 2.54 \\
\hline OLKI & Jokioinen & 119 & 7236 & 14.7 & 0.66 & 0.65 & 1.58 & 3.09 \\
\hline
\end{tabular}

\footnotetext{
${ }^{1}$ The radiosonde trends are calculated using data acquired simultaneous to the GPS observations being compared and are therefore not the
} same for a specific site when it is compared to different GPS sites. 